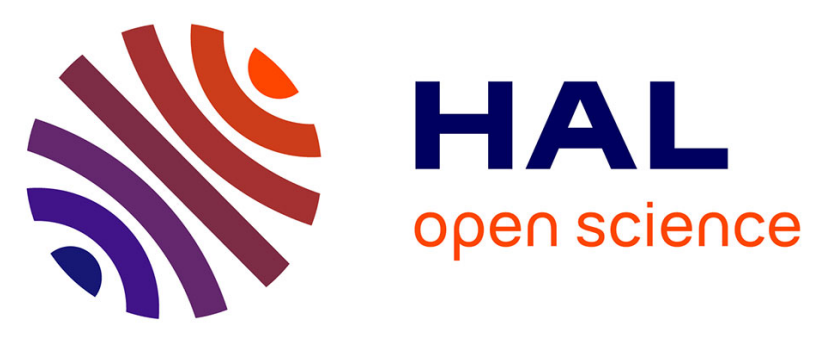

\title{
Comprehensive genetic characterization of hereditary breast/ovarian cancer families from Slovakia
}

Michal Konecny, Miriam Milly, Katarina Zavodna, Eva Weismanova, Jaroslava Gregorova, Iveta Mlkva, Denisa Ilencikova, Juraj Kausitz, Zdena Bartosova

\section{- To cite this version:}

Michal Konecny, Miriam Milly, Katarina Zavodna, Eva Weismanova, Jaroslava Gregorova, et al.. Comprehensive genetic characterization of hereditary breast/ovarian cancer families from Slovakia. Breast Cancer Research and Treatment, 2011, 126 (1), pp.119-130. 10.1007/s10549-010-1325-x . hal00605686

\section{HAL Id: hal-00605686 https://hal.science/hal-00605686}

Submitted on 4 Jul 2011

HAL is a multi-disciplinary open access archive for the deposit and dissemination of scientific research documents, whether they are published or not. The documents may come from teaching and research institutions in France or abroad, or from public or private research centers.
L'archive ouverte pluridisciplinaire HAL, est destinée au dépôt et à la diffusion de documents scientifiques de niveau recherche, publiés ou non, émanant des établissements d'enseignement et de recherche français ou étrangers, des laboratoires publics ou privés. 


\title{
COMPREHENSIVE GENETIC CHARACTERIZATION OF HEREDITARY BREAST/OVARIAN CANCER FAMILIES FROM SLOVAKIA
}

Konecny Michal $^{1}$ *\#, Milly Miriam ${ }^{1}$, Zavodna Katarina ${ }^{1}$, Weismanova Eva ${ }^{1}$, Gregorova Jaroslava ${ }^{1}$, Mlkva Iveta $^{2}$, Ilencikova Denisa $^{3}$, Kausitz Juraj ${ }^{1}$, Bartosova Zdena ${ }^{1}$

${ }^{1}$ Department of Clinical Genetics, St. Elizabeth Cancer Institute, Heydukova 10, 81250 Bratislava, Slovakia

${ }^{2}$ Centre of Clinical Genetics, Faculty Hospital, Americke namestie 3, 81369 Bratislava, Slovakia

${ }^{3}$ Department of Oncological Genetics, National Cancer Institute, Klenova 1, 83310 Bratislava, Slovakia

* Correspondence to: Michal Konecny; Department of Clinical Genetics, St. Elizabeth Cancer Institute, Heydukova 10, 81250 Bratislava, Slovakia; email: mkonecny@ ousa.sk; tel.: +421-2-59 249574

\# The address for offprints: Michal Konecny; Department of Clinical Genetics, St. Elizabeth Cancer Institute, Heydukova 10, 81250 Bratislava, Slovakia; email: mkonecny@ousa.sk; tel.: +421-2-59 249574

Keywords: Hereditary breast ovarian cancer, $B R C A 1, B R C A 2$, mutation, haplotype, MLPA, uncertain variant

\begin{abstract}
Germline mutations in the BRCA1/2 genes account for the majority of hereditary breast ovarian cancer (HBOC). Identification of causal mutations may have significant impact on clinical management of such families. Despite high mutation detection rate, many HBOC cases remain without identified cause. These cases warrant use of several analysis methods, such as those for large genomic rearrangements and DNA copy number changes, or analysis other genes, shown to be associated with increased HBOC risk.

We assessed 585 Slovak HBOC for presence of mutations in BRCA genes. Sequencing revealed mutations in 100 families, representing $17.1 \%$ (88\% and $12 \%$ of mutations were located in BRCA1 and BRCA2, respectively). Four of the mutations, c.80+4del4, c.1938_1947del10 and c.1166delG in BRCA1 and c.6589delA in BRCA2 gene have been described only in Slovak population. Using MLPA analysis, we detected two large genomic rearrangements in 3 families, a deletion of exons 21 and 22, and a rare deletion of a whole BRCAl gene. Twentyseven different variants of uncertain clinical effect (4 novel) and 14 distinct SNP BRCA1 haplotypes were detected. Their potential effect was considered using the prediction software packages Align GVGD, Pmut and Polyphen.

We observed that the best clinical criterion for the initiation of $B R C A l$ analysis is the presence of breast cancer at 40 years of age in the association with the presence of ovarian cancer diagnosed around the age of 50. Conversely, the best clinical criterion for starting with BRCA2 analysis is the presence of breast cancer diagnosed in older age (above 50), or the presence of breast cancer in conjunction with carcinomas at different sites e.g. prostate, colorectum, ovary, uterus. Finally we have seen that the analyses of other HBOC risk gene TP53 and specific mutation in $C H E K 2 *$ c.1100delC in Slovak HBOC families were not efficient since no mutations were found in these genes.
\end{abstract}




\section{INTRODUCTION}

Each year, approximately 2000 of newly diagnosed breast and 450 of ovarian cancer cases appear in Slovakia. The average risk of breast cancer in general Slovak population of women is 4-5\% and of ovarian cancer 2\% [1]. About $5 \%$ of breast or ovarian carcinomas show Mendelian, monogenic, autosomal-dominant inheritance represented by hereditary breast and ovarian cancer syndrome (HBOC), for which two major associated genes (BRCA1, BRCA2) have been identified [2].

The BRCAl gene was localized on chromosome 17q21. It contains 24 exons and encodes a $208 \mathrm{kDa}$ protein composed of 1863 amino acids [3]. The second breast cancer susceptibility gene, the BRCA2 was localized to chromosome 13q12.3 and consists of 27 exons encoding a $380 \mathrm{kDa}$ protein composed of 3418 amino acids [4]. The BRCA proteins are mainly involved in the repair of DNA double-strand breaks (DSB) and in homologous recombination (HR).

About $85 \%$ of causal germline alterations in the BRCAl/2 are frame-shift or nonsense mutations, which lead to the truncation of the protein. The particular mutations differ in distribution depending on ethnicity and geographic location. Some authors believe that missense variants and single nucleotide polymorphisms (SNP) in high penetrance genes may represent additional $\mathrm{HBOC}$ risk factors. Even haplotypes may play a more important role than an individual SNP. BRCAl is hypothesized to be a locus under recombination inhibition, and very few haplotypes have been described here [5]. Frosk et al. [6] in their recent study identified eight distinct haplotypes in $B R C A 1$, mostly derivates of two main lineages. In $B R C A 2,17$ distinct haplotypes were reported, indicating more complex polymorphic pattern in this gene.

The structure of $B R C A 1$ gene exhibiting high density (42\%) of intragenic Alu repeated regions [7] together with the existence of $B R C A 1$ pseudogene located $30 \mathrm{~kb}$ upstream of $B R C A l$ is increasing the likelihood of formation of the large genomic rearrangements (LGRs) by homologous recombination. The proportion of LGRs among the BRCA1 mutations in HBOC families seems to be population-dependent, varying from $2.1 \%$ in a series of Spanish breast/ovarian high-risk families [8] to $36 \%$ in the Dutch patients [9].

Some authors refuse the so called polygenic model for HBOC, in which the risk of breast/ovarian cancer is not influenced by only single high penetrance gene, but rather by a cumulative effect of the variations of several genes with moderate risk. Generally, the products of HBOC moderate risk genes cooperate with BRCA proteins through participation in common protein complexes and intracellular processes, such as DNA repair, transcription, cell cycle control (e.g. ATM, ATR, CHEK2, STK11/LBK1, p53, RAD50, RAD51, BARD1, BAP1, BACH1, CtIP, HDAC1/2, MSH2/6, MLH1, PCNA, PTEN, RNA polymerase II and others) [10].

Our study was primarily focused on the evidence (analysis) of genomic germline mutations in BRCAI/2 genes and other selected HBOC risk genes, such as TP53 and CHEK2*1100delC. In the second step, we aimed to improve clinical interpretation of the role of uncertain missense variants and SNP haplotypes in Slovak HBOC families.

\section{MATERIAL AND METHODS}

\section{Samples and families}

All analysed individuals signed informed consent and were referred for HBOC genetic analysis on the basis of family history of breast/ovarian cancer. All tested families were classified into the groups A and B due to their family history and each group was discriminated into the 4 subgroups according to the number of affected cases 
and the age at diagnosis (Tab. 1). The analysed families and data were collected since 2002 if one of these indication criteria occurred within the family history:

1. Presence of at least 2 patients with diagnosed breast or ovarian cancer among the direct relatives and at least one case diagnosed before age of 45 .

2. Presence of bilateral breast or ovarian cancer among the direct relatives diagnosed at any age.

3. Occurence of duplex breast and ovarian cancer in at least one patient diagnosed at any age.

4. Presence of sporadic breast or ovarian cancer diagnosed at age under 35 years.

5. Presence of at least one case of male breast cancer diagnosed at any age.

Genomic DNA was extracted from peripheral blood samples using QIAamp Mini Kit (Qiagen, Germany).

\section{PCR amplification}

In a primarily used approach, we analysed a whole coding region of the $B R C A$ genes using combination of PCR amplification, SSCP analysis and direct sequencing. BRCAl was analysed in 38 PCR fragments: 21 of them covering coding exons 2-24, with exception of exon 11. Remaining 17 fragments covered exon 11; and were amplified by the nested PCR from two large fragments (11/5F with size of $2059 \mathrm{bp}$, and 11/3F of $1846 \mathrm{bp})$. $B R C A 2$ was analysed in 52 PCR fragments, 20 covering coding exons 2-26 (exon 5 and 6 in one fragment) with exception of large exons, which were sub-divided into smaller fragments (exon 10 into 5, exon 11 into 20, exon 14 and 18 into 2 each, and exon 27 into 3 fragments). Size of all BRCA PCR fragments varied from 162 bp to $450 \mathrm{bp}$. The fragments with atypical mobility or with an atypical number of bands in the SSCP analysis were further sequenced. Primer sequences used for PCR amplification were similar to those published by Friedman et al. [11], but were mostly redesigned using OligoCalc [12].

Each $25 \mu \mathrm{l}$ PCR reaction consisted of following reagents: 1x PCR buffer EXT, $1.5 \mathrm{mM} \mathrm{MgCl}_{2}, 0.2 \mathrm{mM} \mathrm{dNTP}$ mix, 0.6 U EXT polymerase (all Finnzymes), $12.5 \mu \mathrm{M}$ of each primer and $150 \mathrm{ng}$ of DNA. The PCR cycling was performed using thermal profile: $94^{\circ} \mathrm{C} / 4 \mathrm{~min}, 94^{\circ} \mathrm{C} / 30 \mathrm{sec}, 53-65^{\circ} \mathrm{C} / 35-50 \mathrm{sec}, 72^{\circ} \mathrm{C} / 45-80 \mathrm{sec}, 72^{\circ} \mathrm{C} / 7 \mathrm{~min}$, $4^{\circ} \mathrm{C}$ /pause, for 35-45 cycles. In the nested PCR, 20x dilution of large PCR fragments was prepared and a $3 \mu 1$ aliquot was used in the re-amplification of sub-fragments.

\section{Fragment analysis}

Fragment analysis using dye labelled primers was performed for the detection of most relevant frame-shift mutations: c.5266dupC in exon 20, c.68_69delAG in exon 2 of BRCA1 gene and c.1100delC in CHEK2 gene. Primers were labelled with FAM, or VIC.

\section{Allelic discrimination}

Allelic discrimination analysis using TaqMan probes was used for detection of mutation p.Cys61Gly (c.181T $>\mathrm{G}$ ) in exon 5 of BRCA1. The PCR amplification was mixed using 1x TaqMan universal PCR master mix (Applied Biosystems), 1x TaqMan Assay Mix (Applied Biosystems) and $20 \mathrm{ng}$ of DNA in $20 \mu \mathrm{l}$ volume on the ABI 7500 Real-Time analyser (Applied Bosystems) with thermal conditions $95^{\circ} \mathrm{C} / 10$ min., $92^{\circ} \mathrm{C} / 15 \mathrm{sec}$, $60^{\circ} \mathrm{C} / 1$ min., 35 cycles. The positive and negative control samples were always analysed, thus the $\mathrm{Ct}$ and postPCR fluorescence of normal and mutant allele were determined.

\section{MLPA analysis}

Multiplex ligation-dependent probe amplification (MLPA) kit SALSA P002B and SALSA P087 (MRC-Holland) were used for BRCA1 analysis and SALSA P045B (MRC-Holland) for BRCA2 and partial CHEK2 analysis (mutation 1100delC included), according to the manufacturer's protocol. 


\section{Sequencing analysis}

In a novel approach to $B R C A 1$ analysis, the exons $3,11,13,16$ and 18 were directly sequenced without using any pre-screening method. Exon 11 of $B R C A l$ was divided into 7 large fragments ( 347 to $778 \mathrm{bp}$ ) and all were directly sequenced. PCR amplifications for direct sequencing were performed in $25 \mu \mathrm{l}$ PCR reaction volume, using 1x AmpliTaq Gold Mastermix, $12.5 \mu \mathrm{M}$ of each primer and $100 \mathrm{ng}$ of DNA in the thermal profile: $95^{\circ} \mathrm{C} / 5$ min., $95^{\circ} \mathrm{C} / 30$ sec., $58^{\circ} \mathrm{C} / 35-45$ sec., $72^{\circ} \mathrm{C} / 45-55$ sec., $72^{\circ} \mathrm{C} / 7 \mathrm{~min} ., 4^{\circ} \mathrm{C} /$ pause, $30-40$ cycles.

Hot spot exons 5-8 of TP53 gene were also analysed using direct sequencing of two large PCR fragments using primers designed according to the same rules as described previously.

PCR fragments were purified with ExoSAP-IT (USB Corp.) according to the manufacturer's protocol. Subsequently, the sequencing reaction was prepared using 0.2x Big Dye Terminator Cycle Sequencing Kit (Applied Biosystems), 0.75x Sequencing Buffer (Applied Biosystems), $2 \mu \mathrm{M}$ primer and 10-20 ng of PCR product. Sequencing PCR analysis was performed with the following thermal profile: $96^{\circ} \mathrm{C} / 1 \mathrm{~min}$., $96^{\circ} \mathrm{C} / 10 \mathrm{sec}$., $50^{\circ} \mathrm{C} / 5 \mathrm{sec}$., $60^{\circ} \mathrm{C} / 3 \mathrm{~min}$., $4^{\circ} \mathrm{C} /$ pause for 25 cycles. Afterwards, the samples underwent postsequencing purification via columns (Sigma-Aldrich) according to the manufacturer's protocol.

\section{Protein prediction analysis}

Potential clinical effect of variants with unknown significance (UVs) was evaluated by analyses of the severity of the amino acid changes and their conservation across species. These analyses were performed using prediction analysis web tools Align-GVGD [13], PMut [14] and PolyPhen [15].

\section{Nomenclature}

Identified mutations were compared with human BRCA reference sequences, at the cDNA level with NM 007294.3 and U 43746.1. In the case of intronic variations, genomic DNA reference sequences NG 005905.2 and U 94788.1 were used. The HUGO-approved systematic nomenclature, for the description of sequence variants in DNA and protein sequences published by den Dunnen and Paalman [16] was used. Exonic frame-shift and all intronic mutations were assigned at the nucleotide level, while exonic missense and nonsense mutations were marked at the protein level using HUGO-approved systematic nomenclature.

\section{Novel mutations}

The presence of all identified mutations, uncertain variants and polymorphisms was examined in Breast Cancer Information Core database [17], MutDb [18], HGMD database [19] and Swiss-Prot database [20]. Variants assigned as novel were not present in any of these databases.

\section{RESULTS}

Molecular genetic analysis of $585 \mathrm{HBOC}$ families was performed using different approaches (SSCP, fragment analysis, allelic discrimination and direct sequencing and MLPA). Within this set, we identified 100 families with the presence of clearly deleterious mutations (17.1\%). Majority of these 100 families carried mutations in BRCA1 (88\%), remaining $12 \%$ in BRCA2 gene. Furthermore, the analysis of TP53 exons 5-8 in 64 BRCA negative families and the mutation c.1100delC of CHEK2 gene in 159 families, did not reveal any causal mutation.

\section{Pathogenic germline BRCA1 mutations}

Pathogenic mutations in BRCAl were detected by DNA sequencing in $14.5 \%$ (85/585) of analysed families (Table 2). Altogether, 25 different BRCAl mutations were identified, of which 21 caused a premature stop 
codone (84\%), 15 were frameshifts and 6 nonsense mutations. Furthermore, 2 splice-site and 2 missense mutations were detected. The majority of mutations occurred in the largest exon 11 (54\%).

The most frequently detected BRCA1 mutations were c.5266dupC in 32 families (38\%); p.Cys61Gly in 14 families (17\%); c.68_69delAG and c.3700_3704del5 each in 4 families (5\%), and finally c.843_846del4 and c.4243delG in 3 families each (4\%). Altogether, mutations identified in exons 2, 5, 11 and 20 represented $86 \%$ of all BRCA1 mutation-positive Slovak HBOC families (73 out of 85). Mutations c.1166delG, c.1938_1947del10 and c.80+4del4 were previously reported only in Slovak HBOC kindreds [21-23].

The highest detection rate of BRCAl causal mutations (33\%) was observed in families with the presence of duplex breast and ovarian carcinoma in one patient (6 of 18), followed by $33 \%$ in the group of families with the presence of breast and ovarian cancer (25 of 75), $29 \%$ in families with presence of bilateral ovarian cancer (2 of 7), $13 \%$ in families with presence of bilateral breat cancer (11 of 85), 12\% in families with presence of unilateral ovarian cancer ( 6 of 50), and 10\% in families with presence of unilateral breast cancer only (35 of $350)$.

The mean age at the time of cancer diagnosis in patients positive for BRCA1 mutation was 42.7 years (range 21-75). Mean age at diagnosis in the subgroup with the unilateral breast cancer was 40.7 (range 21-66), with the bilateral breast cancer 39.7 (range 30-46), with the unilateral ovarian cancer 51.2 (range 40-75), and with the duplex breast and ovarian cancer 47.5 (49, 50, 41 and 50 years). Bilateral ovarian cancer was diagnosed only in one BRCA1 positive patient (52 years).

The presence of LGRs was analysed in 61 HBOC families negative for BRCA1/2 pathogenic small mutations. The MLPA analysis of both BRCA genes and fragments of CHEK2 gene (promoter, exon 9, exon 10/c.1100delC) was performed simultaneously. Altogether, we identified 3 families positive for the presence of BRCA1 gene LGRs (5\%), while no mutation was detected in BRCA2. Two type of LGRs were present, a deletion of exon 21 and 22 and a deletion of exons 1 through 24. The breakpoints of the detected LGRs were not determined.

\section{Pathogenic germline $B R C A 2$ mutations}

Causal BRCA2 mutations were identified in 12 out of 104 families (11.5\%) (Table 2). Nine different BRCA2 mutations were detected, 6 frameshifts, 2 nonsense mutations and 1 missense mutation of the initial Met codon. Almost all mutations cause a premature stop codon (91\%). The majority of mutations occurred in the largest exon $11(56 \%)$. Mutation c.6589delA was previously reported only in Slovak population [23].

The detection rate $10 \%$ of $B R C A 2$ causal mutations was observed in families with diagnosed breast cancer only (6 of 59), $9 \%$ in families with presence of bilateral breat cancer (2 of 22). In families with the presence of breast and ovarian cancer ( 4 of 14 ), the detection rate was determined to $29 \%$. However, in these cases the presence of male breast cancer, prostate cancer and colorectal cancer was observed as well. No causal mutations were detected in 5 families with the occurrence of duplex breast and ovarian carcinoma in one patient, 3 families with unilateral ovarian cancer and 1 family with bilateral ovarian cancer. Mutation c.9098dupA was detected in family with the presence of male breast cancer.

The mean age at the time of cancer diagnosis of the BRCA2-positive patients was 46 years (33 - 59), while in the subgroup with the unilateral breast cancer diagnosis age was 52.7 (37 - 59). Two positive patients with bilateral breast cancer were diagnosed at mean age of 42.5 years $(33,52)$ and one patient with ovarian cancer at the age of 49 years. 


\section{$B R C A 1 / 2$ variants with uncertain clinical effect}

In 117 HBOC families (out of 585) we identified 19 different types of UVs in BRCA1 gene (20\%). In 19 cases UVs were associated with the presence of pathogenic mutation. The most UVs (84\%) were missense substitutions (16), 16\% intronic variants (1 substitution and 1 insertion) and 1 was an in-frame deletion. The spectrum of detected variants is reported in Table 3. Focused on the localization of UVs in BRCA1 gene, we observed that $79 \%$ of the variants were situated in exon 11 (92 of 117). The most frequently detected UV in BRCA1 gene was p.Gln356Arg, found in 68 families (58\%), however, in 16 cases it was associated with a one of the known pathogenic mutations (p.Cys61Gly, c.5266dupC, c.3700_3704del5, p.Arg1751X). The second most frequent variant was p.Met1652Ile identified in 14 families (12\%) with no detected association to pathogenic mutations. Uncertain variant p.Ser1040Asn was identified in 11 families (9.4\%) and associated with two pathogenic mutations (c.1166delG, p.Leu974X). We have identified three previously unreported novel variants p. Asn630Asp, p. Asn916Thr and p.Thr1246Asn. Variant p.Thr1246Asn was detected in association with mutation c.4065_4068del4 in two families.

BRCA2 UVs were identified in 17 (16\%) out of 104 analysed families. Altogether, 8 different UV types were observed; 7 missense and 1 intronic variant. The most frequently detected UV was c.1909+12delT found in 7 families, in 1 case associated with mutation p.Ser1882X. Variant p.Thr1912Met was found in 4 families, and was not associated with the pathogenic mutation. All other UVs were observed only in one family. Uncertain variant p.Ser2052Leu was identified as novel, not yet published, however, segregation analysis did not reveale any association with breast/ovarian cancer. Missense UVs in the BRCA2 were mostly localized in exon 11 $(71 \%)$.

Prediction analysis of BRCA UVs was based on the comparison of the substituted amino acids and predicted proteins using three software packages: Align-GVGD, Pmut, and Polyphen. Results of the prediction analysis are shown in Table 4. Summarizing prediction results, variants p.Glu1346Gly, p.Ser1512Ile in BRCAl and p.Trp2626Cys, p.Val2908Gly in BRCA2 were predicted as being most probably pathogenic in all used prediction approaches. Uncertain variants p.Arg841Trp in BRCA1 and p.Gly2274Val in BRCA2 were predicted as possible pathogenic.

\section{$B R C A$ SNPs and $B R C A 1$ haplotypes}

Single nucleotide polymorphisms (SNPs) in BRCAl gene are mainly localized together on one allele and thus generate the SNP haplotype. The most frequently identified BRCA1 SNPs were p.Pro871Leu detected in 277 families (47\%), p.Glu1038Gly in 276 families and p.Lys1183Arg in 275 families out of 585 analysed HBOC families. Altogether, 15 different BRCA1 SNPs were identified, of which 6 were silent, 5 missense and 4 intronic substitutions. The silent change p.Pro1562Pro in exon 16 was detected as novel, not yet reported. Major part $(40 \%)$ of detected SNPs were localized in exon 11.

The most frequently identified BRCA2 SNPs were p.His372Asn observed in 83 families (80\%), c.780614T $>\mathrm{C}$ in 54 families (52\%) and p.Lys1132Lys in 53 families (51\%) out of 104 analysed HBOC families. Altogether, 16 different BRCA2 SNPs were detected, 7 silent, 6 missense and 2 intronic substitutions and 1 frame-shift variant. The silent change p.Asp980Asp in exon 11 was detected as novel, not yet reported. The most of identified SNPs were situated in exon $11(50 \%)$ and in exon 10 (19\%).

The haplotype consisting of the 8 SNPs: p.Ser694Ser, p.Leu771Leu, p.Pro871Leu, p.Glu1038Gly, p.Lys1183Arg in exon 11, p.Ser1436Ser in exon 13, p.Ser1613Gly in exon 16 and c.5152+66G/A behind exon 
18 was detected in our set of $B R C A 1$ analysed families as the most frequent one. The second most frequent was the wild-type haplotype without any BRCAI SNP. The spectrum of identified assumed BRCAl haplotypes is shown in Table 5.

\section{Other HBOC risk genes - TP53, CHEK2*1100delC analysis}

The samples from the 61 HBOC BRCA negative families were analysed for the presence of germline mutations in exons 5-8 of TP53 gene. By performing sequencing analysis, no pathogenic mutation was detected. Despite this fact, we identified 6 different variants: 5 intronic variants and one silent variant in exon 6. Silent alteration p.Arg213Arg (c.836G>A) was identified in 2 families. Altogether, detected variants were distributed in $40 \%$ of families (24 of 60). Analysis of the CHEK2 gene using fragment analysis and MLPA analysis was focused on the most frequently reported mutation c.1100delC in exon 10 and revealed no mutation in the 159 BRCA negative families.

\section{DISCUSSION}

Molecular-genetic analysis of BRCA1/2 genes in 585 Slovak HBOC families carried out since 2002 revealed 100 mutation positive families (17.1\%). Eighty five and 12 families carried pathogenic mutations in $B R C A l$ and $B R C A 2$, respectively that were detected by DNA sequencing and 3 families carried LGRs in BRCA1 detected by MLPA. Comparing to other studies, especially from the Central European region, e.g. to Czech population with detection rate ranging from $19.8 \%$ [24] to $29.1 \%$ [25], the detection rate in Slovak HBOC population is lower. Several factors, such as composition of families, number of families, selection criteria or used screening techniques might contribute to this inequality between historically associated populations. The detection rate comparable to ours was reported in the Sicilian population 16\% [26], or in Spain 17.1\% [27].

The highest detection rate of BRCAl pathogenic mutations was observed in families with the presence of both breast and ovarian cancer (33\%) and in families with duplex ovarian and breast carcinoma diagnosed in one patient $(33 \%)$. The lowest rate of only $10 \%$ was present in families with unilateral breast cancer. According to the reported data and also comparing with other studies [25, 26, 28, 29], the presence of ovarian cancer in association with breast cancer serves as a potential predictive factor for BRCAl mutation positivity and represents the strongest indication. On the other hand, the presence of bilateral ovarian (17\%) or breast $(13 \%)$ cancer is still stronger criterion for selection as the familiar unilateral cancer. The highest BRCA2 mutation detection rate of $29 \%$ was observed in families carrying a wide range of carcinomas (breast, ovarian, colorectal, prostate, uterus) and a male breast cancer. Exclusive presence of bilateral breast cancer (9\%) and unilateral breast cancer (10\%) also shown association with several mutations, however, the exclusive presence of ovarian cancer does not seem to be an indication.

Mean age of the BRCAl-positive patients was 43 years, ranging from 21 to 75 years. Mean age at the time of diagnosis was higher in BRCAl-negative cases (44 years, 21-70) than in BRCAl-positive cases (40 years, 21-66). Surprisingly, the mean age of patients at ovarian cancer diagnosis in BRCAl-negative cases was 45 years (2275), but in BRCA1 positive cases was nearly 50 years (unilateral ovarian cancer - 51.2, duplex breast and ovarian cancer -49.2 and bilateral ovarian cancer -52 years). This observation is indicating that the presence of $B R C A 1$ pathogenic mutations is more likely in the patients with breast cancer at 40 years and ovarian cancer at relatively 
higher age of 50 years. Thus, sporadic ovarian cancer cases diagnosed at very young age (under 40 years) probably should not be indicated to $B R C A$ analysis because their cancers may be caused by the environmental and lifestyle risk factors (smoking, contraceptives etc.).

According to our data, the BRCAl pathogenic mutations in Slovak HBOC population may be divided into following groups:

- $\quad$ Frequent mutations considered as Slavic founder: p.Cys61Gly and c.5266dupC.

- Relatively frequent mutations probably drifted to Slovak population from neighbouring populations: c.68_69delAG (Ashkenazi), c.843_846del4 (Austrian, German), c.2068delA (German), c.3700_3704del5 (Czech), c.4243delG and p.Arg1443X (French, Quebec-Canadian), c.4065_4068del4 (Western Europe).

- $\quad$ Rare mutations specific for Slovak HBOC population: c.80+4del4, c.1166delG, c.1938_1947del10.

- Rare mutations specific for "Czechoslovak" HBOC population: p.Cys39Arg, p.Gln563X, c.2488_2497dup10, p.Gln1447X, c.4986+4A>T.

- Very rare mutations: c.1953_1956del4, p.Leu974X, c.3016_3019del4, c.3018_3021del4, c.3770_3771del2, c.4124delG; c.4867+4A>T; c.5084_5085del2 and p.Arg1751X.

The most frequently found BRCAl mutations responsible for the majority of Slovak HBOC cases are c.5266dupC in 32 families (38\%); p.Cys61Gly in 14 families (17\%); c.68_69delAG, c.3700_3704del5 each in 4 families (5\%), and finally c.843_846del4, c.4243delG each in 3 families (4\%). Altogether, these six mutations accounted for $73 \%$ of the BRCA1-positive HBOC families. Similarly high frequencies of c.5266dupC and p.Cys61Gly mutations were reported in other studies of Central European populations [24, 25, 30] which is strongly indicating that at least these two mutations are caused by founder efect.

Other pathogenic mutations (27\%) identified only in one or two families fall in a group of Slovak HBOC low frequency BRCA1 mutations, though some of them were detected in neighbouring populations as well. Machackova et al. [25] identified mutations p.Cys39Arg, p.Gln563X, c.2488_2497dup10, c.3700_3704del5 and p.Gln1447X in Czech population, which is probably the closest to the Slovak population. Mutations c.4065_4068de14 and p.Arg1443X were found in Sweden [31], p.Arg1443X in the Sicilian population [26] as well as in the French population as a founder mutation [32]. Other Slovak low frequency BRCA1 pathogenic mutations were not occuring in any European HBOC report.

All detected missense causal mutations were localized in a highly conserved structure of $\mathrm{C}_{3} \mathrm{HC}_{4}$ RING domain of BRCA1, which has been described as $\mathrm{Zn}^{2+}$ binding site of RING domain for dimerization with BARD1 [33]. Highly conserved residues C39, H41, C61, and C64 are localized in the regions where mutations p.Cys39Arg, p.Cys61Gly were observed. The small deletion c.80+4del4 results in the skipping of exon 2 and subsequent generation of an aberrant translational start in exon 5.

Interestingly, a minimum of nonsense mutations was identified in exon 11 [21, 25, 26, 28, 29] in comparison to other types of mutations in this exon and no causal missense mutations were present in this exon due to the lack of highly conserved domain in this region. However, it can not be excluded that some of the frequently occurring missense variants with uncertain clinical significance localized mainly in exon 11 (and similarly in exon 16), might have some effect on the protein function and thus play a role in the development of HBOC phenotype. 
Altogether, 9 different BRCA2 mutation types in 12 families were identified in the set of 104 HBOC families (11.5\%). Generally, the most of the pathogenic mutations in this gene in our series are localized in exon 11 , similarly to many other reports $[31,34,35]$. Interestingly, $44 \%$ of $B R C A 2$ pathogenic mutations detected in our cohort of patients have also been reported in Czech HBOC population [26, 36] confirming the genetic relationship of these two neighbouring populations.

It seems that LGRs do not represent frequent mutational events in Slovak HBOC families (5\%). Compared to other studies, our LGR detection rate was similar to the one in Czech 5.8\% [37] or German population 5.3\% [38]. Deletion of exons 21-22 in BRCAl gene was previously reported in Czech population [37]. This deletion affects the C-terminal BRCT domain of BRCA1 protein and result in the skipping of 43 amino acids from the position 1760 to 1802 . This loss of a part of the conservative BRCT domain is suggested to have a cancer susceptibility effect. Deletion of exons 1 through 24 represents a very rare event and was previously reported in one Spain [8] and one German family [39]. Identifying the second family with the same deletion of BRCAI allele living in the same geographical area raises the question whether these two mutations are exactly identical, what can be answered after the determiantion of breakpoints. Alternatively, testing of families relationship and haplotype analysis of family members may reveal wether this mutation is family specific or represents a new Slovak founder mutation.

Mutation detection rate of BRCA1/2 uncertain variants in Slovak HBOC families is relatively high, $23 \%$ (133 families), in contrast to recent studies reporting substantially lower frequencies: $6.8 \%$ in Spanish population [40], $5.7 \%$ in Sicilian population [26], 5.1\% in Indonesian population [41], only $1.5 \%$ in both, New Zealand and Australian populations [42]; and $0.86 \%$ in US HBOC families [43]. A big deviation in the detection rates may reflect sensitivity of detection techniques used in the different studies. In some studies, the identification of mutations in exon 11 was based on the performance of techniques such as SSCP, PTT, DGGE, CSGE [40] or DHPLC [29, 41]. We assume that employment of direct sequencing for analysis of large exons in our study resulted into the identification of a broader spectrum of missense UVs.

However, interpretation of uncertain variants still remains problematic. Prediction of the effect of UVs in functional analysis studies and in the prediction software may generate controversial results. Complex evaluation of missense UVs should consist of the combination of several approaches based on, but not limited to cosegregation analysis of UVs with disease in a family, loss of heterozygosity in tumors, determination of the frequency of variant in unaffected controls, in silico prediction analysis, functional assays [44]. In our study, we analysed the BRCA UVs using prediction software [13-15], next by studying the association of UVs with pathogenic mutation and number of entries in the BIC database and finally, if possible, by performing a cosegregation analyses of UVs with the disease. Taking in account the results of our examinations, we suggest that BRCA2 variants p.Gly2274Val, p.Trp2626Cys and p.Val2908Gly, and BRCA1 variants p.Glu1346Gly and p.Ser1512Ile are very likely pathogenic. Interestingly, relatively high portion of variants in $B R C A 2$ gene are predicted as possible pathogenic (Table 4). However, these predictions should be confirmed by the segregation analysis of oncological disease within the affected family and other type of analyses in the future.

It is believed that the explanation of discrepancy between the frequency of hereditary breast/ovarian cancer families and detected $B R C A$ mutations may lie in a polygenic heredity with many non-BRCA moderate risk 
susceptibility genes, although the existence of an autosomal recessive mendelian allele cannot be excluded [45, 46]. In this sense, breast cancer represents a complex genetic disease. Moderate risk candidate genes, which presumably alter breast cancer predisposition, may be found in a variety of pathways, ranging from the detoxification of environmental carcinogens to the steroid hormone metabolism and the DNA damage repair [47]. On the other hand, we suggest that many features of $B R C A$ genes such as promoter sequences, epigenetic changes, microRNA, uncertain variants, intronic splice variants or SNP haplotypes may represent additional factors that might seriously alter the risk of breast/ovarian cancer onset. We hypothesize that so-called „BRCA intra-gene modifier factors" should be more investigated and may bring alternatives to polygenic models. SNP haplotypes in BRCA genes are mostly determined by the presence of a set of SNPs, which are grouped on one allele and inherited in a linkage. Haplotypes may play a more important role than individual SNPs and may alter the risk of breast/ovarian cancer. Identification of such haplotypes depends on the analysis of large number of samples to obtain sufficient amount of data. BRCAl gene is a relatively optimal example since this gene is hypothesized to be a locus under recombination inhibition with very few haplotypes described. In fact, only one haplotype block and two major haplotypes have been shown to exist in Caucasians [5]. However, in BRCA2 gene the situation concerning haplotypes is more complex, reflecting the existence of a large number of variations [49].

We observed the main haplotypes of BRCA1 gene in Slovak HBOC families, their homozygous or heterozygous status and we tried to interpret their possible clinical effect and/or identify a possible pathogenic haplotype. The most frequent haplotype (31.4\%) seen in Slovak HBOC families consists of SNP variants: p.Ser694Ser, p.Leu771Leu, p.Pro871Leu, p.Glu1038Gly, p.Lys1183Arg in exon 11, p.Ser1436Ser in exon 13, p.Ser1613Gly in exon 16 and intronic variants c.4987-68G $>\mathrm{A}$ in intron 16, c.5152+66G $>\mathrm{A}$ in intron 18 . The presence of a set of variants on both alleles (in homozygous stage) or the presence of two different SNP haplotypes (each in heterozygous stage) may importantly alter the biological pathways dependent on the BRCA1 protein. Interestingly, the pathogenic mutation p.Cys61Gly was in all 13 cases associated with the same haplotype with uncertain variant p.Gln356Arg. The significance of this observation and our assumptions may be supported by future investigations involving more functional and segregation analyses.

\section{CONCLUSIONS}

The analysis of $B R C A 1$ and $B R C A 2$ genes in 585 Slovak HBOC families revealed the presence of deleterious mutations in 100 families, representing a prevalence of $17.1 \%$. In total, 25 and 12 different BRCA1 and BRCA2 mutations, respectively, that were detected by DNA sequencing and 2 LGRs in BRCA1 gene were found by MLPA.. Mutations c.5266dupC detected in 38\%; p.Cys61Gly in 17\%; c.68_69delAG, c.3700_3704del5 each in $5 \%$ and finally c.843_846del4, c.4243delG each in $4 \%$ of families represent high-frequency Slovak BRCA1 pathogenic mutations. Altogether, these five BRCAl mutations were present in $73 \%$ of all BRCAl positive HBOC families.

We observed that besides the familial occurrence of the cancer disease, other important clinical criterion for $B R C A 1$ analysis is the presence of a breast cancer diagnosed around the age of 40 , in association with the presence of ovarian cancer diagnosed around 50 years of age. Conversely, for BRCA2 analysis, the diagnosis of breast cancer diagnosed at older age, around age of 50, or the presence of breast cancer in association with broader spectrum of other carcinomas (prostate, colorectum, ovaria, uterus) was clinically most indicative. 
In silico prediction analysis complemented with segregation analysis may represent the model of standard diagnostic protocol for interpretation of exonic missense uncertain variants. Haplotypes of BRCAl gene may represent potential modifiers of cancer risk in the future, as a part of the concept of BRCA intra-gene modifier factors. This approach should be based on the complex genomic analysis of both genes (promoter, epigenetic, intronic, microRNA, UVs, SNP haplotypes). Finally, we conclude that the analysis of other HBOC risk genes TP53 and CHEK2*c.1100delC is not efficient in Slovak HBOC families.

This is the first comprehensive study of molecular-genetic features of HBOC syndrome in Slovak families which includes deleterious mutations, variants with uncertain clinical significance and SNP haplotypes.

\section{REFERENCES}

1. Ondrusova, M, Plesko, I, Safaei-Diba, Ch, Obsitnikova, A, Stefanakova, D, Ondrus, D (2007) Comprehensive analysis of incidence and mortality of malignant tumours in the Slovak Republic. [online] Bratislava, National Cancer Registry of the Slovak Republic, NHIC, http://www.nor-sk.org/.

2. Antoniou, A, Pharoah, P, D, Narod, S, Risch, H, A., Eyfjord, J, E, Hopper, J, L, Loman, N, Olsson, H, Johannsson, O, Borg, A, Pasini, B, Radice, P, Manoukian, S, Eccles, D, M, Tang, N, Olah, E, AntonCulver, H, Warner, E, Lubinski, J, Gronwald, J, Gorski, B, Tulinius, H, Thorlacius, S, Eerola, H, Nevanlinna, H, Syrjäkoski, K, Kallioniemi, O, P, Thompson, D, Evans, C, Peto, J, Lalloo, F, Evans, D, G, Easton, D, F (2003) Average risks of breast and ovarian cancer associated with BRCAl or BRCA2 mutations detected in case Series unselected for family history: a combined analysis of 22 studies. Am J Hum Genet 72(5): 1117-30.

3. Miki, Y, Swensen, J, Shattuck-Eidens, D, Futruel, P, A, Harshman, K, Tavtigian, S, Liu, Q, Cochran, C, Bennett, L, M, Ding, W, Bell, R, Rosenthal, J, Hussey, C, Tran, T, McClure, M, Frye, C, Hattier, T, Phelps, R, Haugen-Strano, A, Katcher, H, Yakumo, K, Gholami, Z, Schaffer, D, Stone, S, Bayer, S, Wray, C, Bogden, R, Dayananth, P, Ward, J, Tonin, P, Narod, S, Bristow, P, K, Norris, F, H, Helvering, L, Morrison, P, Rosteck, P, Lai, M, Barrett, J, C, Lewis, C, Neuhausen, S, Cannon-Albright, L, Goldgar, D, Wiseman, R, Kamb, A, Skolnick, M, H (1994) A strong candidate for the breast and ovarian cancer susceptibility gene BRCA1. Science 266: 66-71.

4. Wooster, R, Neuhausen, S, L, Mangion, J, Quirk, Y, Ford, D, Collins, N, Nguyen, K, Seal, S, Tran, T, Averill, D (1994) Localization of a breast cancer susceptibility gene BRCA2, to chromosome 13q12-13. Science. 265: 2088-90.

5. Cox, D, G, Kraft, P, Hankinson, S, E, Hunter, D, J (2005) Haplotype analysis of common variants in the BRCA1 gene and risk of sporadic breast cancer. Breast Cancer Res 7(2): R171-5.

6. Frosk, P, Burgess, S, Dyck, T, Jobse, R, Spriggs, E, L (2007) The use of ancestral haplotypes in the molecular diagnosis of familial breast cancer. Genet Test 11(3): 208-15.

7. Welcsh, P, L, King, M, C (2001) BRCA1 and BRCA2 and the genetics of breast and ovarian cancer. Hum Mol Genet 10: 705-13.

8. De la Hoya M, Gutiérrez-Enríquez S, Velasco E, Osorio A, Sánchez de Abajo A, Vega A, Salazar R, Esteban E, Llort G, Gonzalez-Sarmiento R et al (2006) Genomic rearrangements at the BRCA1 locus in Spanish families with breast/ovarian cancer. Clin Chem 52: 1480-1485. 
9. Petrij-Bosch, A, Peelen, T, van Vliet, M, van Eijk, Olmer, R, Drusedau, M, Hogervorst, F, B, Hageman, S, Arts, P, J, Lingtenberg, M, J, et al (1997) BRCA genomic deletions are major founder mutations in Dutch breast cancer patients. Nat Genet 17: 341-355

10. Narod, S, A, Foulkes, W, D (2004) BRCA1 and BRCA2: 1994 and beyond. Nature Rev 4: 665-76.

11. Friedman, L, S, Ostermeyer, E, A, Szabo, C, I, Dowd, P, Lynch, E, D, Rowell, S, E, King, M, C (1994) Confirmation of BRCAl by analysis of germline mutations linked to breast and ovarian cancer in ten families. Nat Genet 8:399-404.

12. OligoCalc, http://www.basic.northwestern.edu/ biotools/oligocalc.html

13. AGVGD, http://agvgd.iarc.fr/agvgdinput.php

14. Pmut, http://mmb2.pcb.ub.es:8080/Pmut

15. PolyPhen, http://genetics.bwh.harvard.edu/pph

16. den Dunnen, J, T, Paalman, M, H (2003) Standardizing mutation nomenclature: why bother? Hum Mutat 22(3): 181-2.

17. Breast Cancer Information Core database, http://research.nhgri.nih.gov/bic/

18. MutDb database, http://www.mutdb.org/

19. HGMD database, http://www.hgmd.cf.ac.uk/ac/index.php

20. Swiss-Prot database, http://expasy.org/sprot/

21. Konecny, M, Vizvaryova, M, Weismanova, E, Ilencikova, D, Mlkva, I, Weismann, P, Machackova, G, Kausitz, J (2007) The spectrum and incidence of BRCAl pathogenic mutations in slovak breast/ovarian cancer families. Neoplasma 54: 137-142.

22. Cierniková S, Tomka M, Sedláková O, Reinerová M, Stevurková V, Kovác M, Cente M, Ilenciková D, Bella V, Zajac V (2003) The novel exon 11 mutation of BRCAl gene in a high-risk family. Neoplasma 50(6):403-7.

23. Konecny M, Vizvaryova M, Zavodna K, Behulova R, Gerykova-Bujalkova M, Krivulcik T, Cisarik F, Kausitz J, Weismanova E (2010) Identification of a novel mutations $B R C A I * \mathrm{c} .80+3 \mathrm{del} 4$ and BRCA2*c.6589delA in Slovak HBOC families. Breast Cancer Res Treat 119(1):233-7.

24. Wagner, T, M, Moslinger, R, A, Muhr, D, Langbauer, G, Hirtenlehner, K, Concin, H, Doeller, W, Haid, A, Lang, A, H, Mayer, P, Ropp, E, Kubista, E, Amirimani, B, Helbich, T, Becherer, A, Scheiner, O, Breiteneder, H, Borg, A, Devilee, P, Oefner, P, Zielinski, C (1998) BRCAl-related breast cancer in Austrian breast and ovarian cancer families: specific BRCAl mutations and pathological characteristics. Int J Cancer 77:354-60.

25. Machackova, E, Foretova, L, Lukesova, M, Vasickova, P, Navratilova, M, Coene, I, Pavlu, H, Kosinova, V, Kuklova, J, Claes, K (2008) Spectrum and characterisation of BRCA1 and BRCA2 deleterious mutations in high-risk Czech patients with breast and/or ovarian cancer. BMC Cancer 8: 140.

26. Russo, A, Calò, V, Agnese, V, Bruno, L, Corsale, S, Augello, C, Gargano, G, Barbera, F, Cascio, S, Intrivici, C, Rinaldi, G, Gulotta, G, Macaluso, M, Surmacz, E, Giordano, A, Gebbia, N, Bazan, V (2007) BRCA1 genetic testing in 106 breast and ovarian cancer families from Southern Italy (Sicily): a mutation analyses. Breast Cancer Res Treat 105(3):267-76. 
27. Llort, G, Munoz, C, Y, Tuser, M, P, Guillermo, I, B, Lluch, J, R, Bale, A, E, Franco, M, A (2002) Low frequency of recurrent BRCA1 and BRCA2 mutations in Spain. Hum Mutat 19: 307.

28. Krajc, M, Teugels, E, Zgajnar, J, Goelen, G, Besic, N, Novakovic, S, Hocevar, M., De Grève, J (2008) Five recurrent $B R C A 1 / 2$ mutations are responsible for cancer predisposition in the majority of Slovenian breast cancer families. BMC Med Genet 9:83.

29. Miramar, M, D, Calvo, M, T, Rodriguez, A, Antón, A, Lorente, F, Barrio, E, Herrero, A, Burriel, J, García de Jalón, A (2008) Genetic analysis of BRCA1 and BRCA2 in breast/ovarian cancer families from Aragon (Spain): two novel truncating mutations and a large genomic deletion in BRCA1. Breast Cancer Res Treat 112(2):353-8.

30. Perkowska, M, Brozek, I, Wysocka, B, Haraldsson, K, Sandberg, T, Johansson, U, Sellberg, G, Borg, A, Limon, J (2003) BRCA1 and BRCA2 mutation analysis in breast-ovarian cancer families from northeastern Poland. Hum Mutat 2: 553-4.

31. Bergman, A, Flodin, A, Engwall, Y, Arkblad, E, L, Berg, K, Einbeigi, Z, Martinsson, T, Wahlstrom, J, Karlsson, P, Nordling, M (2005) A high frequency of germline BRCA1/2 mutations in western Sweden detected with complementary screening techniques. Fam Cancer 4:89-96.

32. Vezina, H, Durocher, F, Dumont, M, Houde, L, Szabo, C, Tranchant, M, Chiquette, J, Plante, M, Laframboise, R, Lepine, J, Nevanlinna, H, Stoppa-Lyonnet, D, Goldgar, D, Bridge, P, Simard, J (2005) Molecular and genealogical characterization of the R1443X BRCAl mutation in high-risk FrenchCanadian breast/ovarian cancer families. Hum Genet 117: 119-132.

33. Ruffner, H, Joazeiro, C, A, Hemmatim, D, Hunter, T, Verma, I, M (2001) Cancer-predisposing mutations within the RING domain of BRCA1: loss of ubiquitin protein ligase activity and protection from radiation hypersensitivity. Proc Natl Acad Sci USA 98(9): 5134-9.

34. Pohlreich, P, Zikan, M, Stribrna, J, Kleibl, Z, Janatova, M, Kotlas, J, Zidovska, J, Novotny, J, Petruzelka, L, Szabo, C, Matous, B (2005) High proportion of recurrent germline mutations in the BRCA1 gene in breast and ovarian cancer patients from the Prague area. Breast Cancer Res 7: 728-36.

35. Kataki, A, Gomatos, I, Pararas, N, Armakolas, A, Panousopoulos, D, Karantzikos, G, Voros, D, Zografos, G, Markopoulos, C, Leandros, E, Konstadoulakis, M (2005) Identification of germline $B R C A 1$ and BRCA2 genetic alterations in Greek breast cancer moderate-risk and low-risk individualscorrelation with clinicopathological data. Clin Genet 67(4):322-9.

36. Foretova, L, Machackova, E, Navratilova, M, Pavlu, H, Hruba, M, Lukesova, M, Valik, D (2004) $B R C A 1$ and BRCA2 mutations in women with familial or early-onset breast/ovarian cancer in the Czech Republic. Hum Mutat 23: 397-398.

37. Vasickova, P, Machackova, E, Lukesova, M, Damborsky, J, Horky, O, Pavlu, H, Kuklova, J, Kosinova, V, Navratilova, M, Foretova, L (2007) High occurrence of BRCAl intragenic rearrangements in hereditary breast and ovarian cancer syndrome in the Czech Republic. BMC Med Genet 8:32.

38. Hartmann, C, John, A, L, Klaes, R, Hofmann, W, Bielen, R, Koehler, R, Janssen, B, Bartram, C, R, Arnold, N, Zschocke, J (2004) Large BRCA1 gene deletions are found in 3\% of German high-risk breast cancer families. Hum Mutat 24(6): 534.

39. Engert, S, Wappenschmidt, B, Betz, B, Kast, K, Kutsche, M, Hellebrand, H, Goecke, T, O, Kiechle, M, Niederacher, D, Schmutzler, R, K, Meindl, A (2008) MLPA screening in the BRCAl gene from 1,506 
German hereditary breast cancer cases: novel deletions, frequent involvement of exon 17, and occurrence in single early-onset cases. Hum Mutat 29(7): 948-58.

40. Díez, O, Osorio, A, Durán, M, Martinez-Ferrandis, J, I, de la Hoya, M, Salazar, R, Vega, A, Campos, B, Rodríguez-López, R, Velasco, E, Chaves, J, Díaz-Rubio, E, Jesús Cruz, J, Torres, M, Esteban, E, Cervantes, A, Alonso, C, San Román, J, M, González-Sarmiento, R, Miner, C, Carracedo, A, Eugenia Armengod, M, Caldés, T, Benítez, J, Baiget, M (2003) Analysis of BRCA1 and BRCA2 genes in Spanish breast/ovarian cancer patients: a high proportion of mutations unique to Spain and evidence of founder effects. Hum Mutat 22(4): 301-12.

41. Purnomosari, D, Pals, G, Wahyono, A, Aryandono, T, Manuaba, T, W, Haryono, S, J, van Diest, P, J (2007) BRCA1 and BRCA2 germline mutation analysis in the Indonesian population. Breast Cancer Res Treat 106(2): 297-304.

42. Tesoriero, A, A, Wong, E, M, Jenkins, M, A, Hopper, J, L, Brown, M, A, Chenevix-Trench, G, Spurdle, A, B, Southey, M, C, kConFab (2005) Molecular characterization and cancer risk associated with $B R C A 1$ and BRCA2 splice site variants identified in multiple-case breast cancer families. Hum Mutat 26(5): 495.

43. Pal, T, Permuth-Wey, J, Betts, J, A, Krischer, J, P, Fiorica, J, Arango, H, LaPolla, J, Hoffman, M, Martino, M, A, Wakeley, K, Wilbanks, G, Nicosia, S, Cantor, A, Sutphen, R (2005) BRCAl and BRCA2 mutations account for a large proportion of ovarian carcinoma cases. Cancer 104(12):2807-16.

44. Chenevix-Trench, G, Healey, S, Lakhani, S, Waring, P, Cummings, M, Brinkworth, R, Deffenbaugh, A, M, Burbidge, L, A, Pruss, D, Judkins, T, Scholl, T, Bekessy, A, Marsh, A, Lovelock, P, Wong, M, Tesoriero, A, Renard, H, Southey, M, Hopper, J, L, Yannoukakos, K, Brown, M, Easton, D, Tavtigian, S, V, Goldgar, D, Spurdle, A, B, kConFab Investigators (2006) Genetic and histopathologic evaluation of BRCA1 and BRCA2 DNA sequence variants of unknown clinical significance. Cancer Res 66(4): 2019-27.

45. Pharoah, P, D, Antoniou, A, Bobrow, M, Zimmern, R, L, Easton, D, F, Ponder, B, A (2002) Polygenic susceptibility to breast cancer and implications for prevention. Nat Genet 31: 33-6.

46. Antoniou, A, C, Pharoah, P, P, Smith, P, Easton, D, F (2004) The BOADICEA model of genetic susceptibility to breast and ovarian cancer. Br J Cancer 91(8): 1580-90.

47. Syamala, V, S, Sreeja, L, Syamala, V, Raveendran, P, B, Balakrishnan, R, Kuttan, R, Ankathil, R (2008) Influence of germline polymorphisms of GSTT1, GSTM1, and GSTP1 in familial versus sporadic breast cancer susceptibility and survival. Fam Cancer 7(3): 213-20.

48. Ward B, D, Hendrickson B, C, Judkins T, Deffenbaugh A, M, Leclair B, Ward B, E, Scholl T (2005) A multi-exonic BRCA1 deletion identified in multiple families through single nucleotide polymorphism haplotype pair analysis and gene amplification with widely dispersed primer sets. J Mol Diagn 7(1):139-42.

Table 1. The distribution of breast/ovarian cancer families in the groups due to family history.

\begin{tabular}{|lllll|}
\hline $\begin{array}{l}\text { Family } \\
\text { history }\end{array}$ & Families & Characterization & $\begin{array}{l}\text { Number of } \\
\text { families }\end{array}$ \\
\hline A. Strong & A1 & $\begin{array}{l}\text { At least 2 cases of breast or ovarian cancer but 1 under the age of 45, the } \\
\text { rest under the age of } 65 \text { years }\end{array}$ & 248 \\
\hline
\end{tabular}




\begin{tabular}{|c|c|c|c|c|}
\hline & $\mathrm{A} 2$ & At least 1 case with breast and ovarian cancer at the age under 65 years & \multirow{2}{*}{$\begin{array}{l}10 \\
79\end{array}$} & \\
\hline & A3 & $\begin{array}{l}\text { Bilateral form of breast or ovarian cancer under the age of } 65 \text { years } \\
\text { (bilateral form up the age } 65 \text { years was counted as } 2 \text { independent cases) }\end{array}$ & & \\
\hline & A4 & Presence of breast cancer in male patient & 1 & \\
\hline \multirow[t]{4}{*}{ B. Medium } & B1 & $\begin{array}{l}\text { At least } 3 \text { cases of breast or ovarian cancer up to age } 45 \text { and under } 65 \\
\text { years }\end{array}$ & 43 & \multirow{4}{*}{193} \\
\hline & $\mathrm{B} 2$ & One case of breast or ovarian cancer under the age of 45 years & 70 & \\
\hline & B3 & At least 2 cases of breast, ovarian or prostate cancer at the age of 65 & 60 & \\
\hline & B4 & $\begin{array}{l}\text { Only } 1 \text { case of breast or ovarian cancer up the age of } 45 \text { and under } 65 \\
\text { years with at least } 2 \text { cases of other associated carcinomas at any age }\end{array}$ & 20 & \\
\hline
\end{tabular}

\section{Table 2. The spectrum of $B R C A 1 / 2$ pathogenic mutations in Slovak HBOC families.}

Abbreviations: BIC, Breast information core; aa, amino acid; Fam., number of families; Sam., number of samples; del, deletion; dup, duplication; *, novel mutation; IVS, Intron Variable Site; FS, frame-shift; IS, intronic splicing; MS, missense; NS, nonsense; mut., mutation. 


\begin{tabular}{|c|c|c|c|c|c|c|}
\hline No & $\begin{array}{l}\text { Approved } \\
\text { nomenclature }\end{array}$ & $\begin{array}{l}\text { BIC traditional } \\
\text { nomenclature }\end{array}$ & $\begin{array}{l}\text { Mutation type; predicted } \\
\text { aa effect }\end{array}$ & Exon & Fam. & World appearance \\
\hline \multicolumn{7}{|c|}{ BRCA1 pathogenic mutations } \\
\hline 1 & c.68_69delAG & 185delAG & FS; p.Glu23ValfsX16 & 2 & 4 & Ashkenazi \\
\hline 2 & c.80+4del4 & 199+4delAGTC & IS, exon 2 skipping & $2 / 3$ & 1 & Only in Slovakia \\
\hline 3 & c.115T $>\mathrm{C}$ & $234 \mathrm{~T}>\mathrm{C}$ & MS; p.Cys39Arg & 3 & 1 & Central/ Eastern EU \\
\hline 4 & c.181T $>$ G & $300 \mathrm{~T}>\mathrm{G}$ & MS; p.Cys61Gly & 5 & 14 & EU and USA \\
\hline 5 & c.843_846del4 & 962delCTCA & FS; p.Ser281SerfsX15 & 11 & 3 & Austria \\
\hline 6 & c.1166delG & $1285 \mathrm{delG}$ & FS; p.Ser389MetfsX4 & 11 & 1 & Only in Slovakia \\
\hline 7 & c. $1687 \mathrm{C}>\mathrm{T}$ & $1806 \mathrm{C}>\mathrm{T}$ & NS; p.Gln563X & 11 & 1 & Czech, Austrian, German \\
\hline 8 & c.1938_1947del10 & 2057del10CAGTGAAGAG & FS; p.Ser646ArgfsX2 & 11 & 2 & Only in Slovakia \\
\hline 9 & c.1953_1956del4 & 2072delGAAA & FS; p.Lys651LysfsX48 & 11 & 1 & Western EU, USA \\
\hline 10 & c.2068delA & $2187 \mathrm{delA}$ & FS; p.Lys690LysfsX9 & 11 & 2 & German \\
\hline 11 & c.2488_2497dup10 & 2607dupAAGTATCCAT & FS; p.Lys833LysfsX2 & 11 & 1 & Czech \\
\hline 12 & c.2921T A & $3040 \mathrm{~T}>\mathrm{A}$ & NS; p.Leu974X & 11 & 2 & Australian \\
\hline 13 & c.3016_3019del4 & 3135delCATT & FS; p.His1006GlnfsX16 & 11 & 1 & Austria \\
\hline 14 & c.3018_3021del4 & 3137delTTCA & FS; p.His1006GlnfsX16 & 11 & 1 & Western Europe \\
\hline 15 & c.3700_3704del5 & 3819delGATAA & FS; p.Val1234GlnfsX7 & 11 & 4 & Central/Eastern EU, Poland \\
\hline 16 & c.3770_3771del2 & 3889delAG & FS; p.Glu1257GlyfsX8 & 11 & 1 & Central/Eastern EU \\
\hline 17 & c.4065_4068del4 & 4184delTCAA & FS; p.Asp1355LysfsX9 & 11 & 2 & $\begin{array}{l}\text { Norwegian, British, French/ } \\
\text { Canadian, Central EU }\end{array}$ \\
\hline 18 & c.4243delG & 4362delG & FS; p.Glu1415LysfsX3 & 13 & 3 & Slovak, German \\
\hline 19 & c. $4327 \mathrm{C}>\mathrm{T}$ & $4446 \mathrm{C}>\mathrm{T}$ & NS; p.Arg1443X & 13 & 1 & $\begin{array}{l}\text { France, French/Canadian; } \\
\text { Finland }\end{array}$ \\
\hline 20 & c. $4339 \mathrm{C}>\mathrm{T}$ & $4458 \mathrm{C}>\mathrm{T}$ & NS; p.Gln1447X & 13 & 1 & African, Czech \\
\hline 21 & c. $4986+4 \mathrm{~A}>\mathrm{T}$ & $5105+4 \mathrm{~A}>\mathrm{T}$ & IS, exon 16 skipping & $16 / 17$ & 2 & Central-Eastern Europe \\
\hline 22 & c.5084_5085del2 & 5203delTT & NS; p.Phe1695CysfsX2 & 18 & 1 & Ashkenazi, Central EU \\
\hline 23 & c.5251C>T & $5370 \mathrm{C}>\mathrm{T}$ & NS; p.Arg1751X & 20 & 2 & Finland, Greece, Western EU \\
\hline 24 & c.5266dupC & 5385dupC & FS; p.Gln1756ProfsX73 & 20 & 32 & Founder in EU, Ashkenazi \\
\hline 25 & c.5511G $>A$ & $5630 \mathrm{G}>\mathrm{A}$ & NS; p.Trp1837X & 24 & $\mathbf{1}$ & Czech, French \\
\hline \multicolumn{7}{|c|}{ BRCA2 pathogenic mutations } \\
\hline 1 & c. $3 \mathrm{G}>\mathrm{A}$ & $231 \mathrm{G}>\mathrm{A}$ & MS; p.Met1Ile & 2 & $\mathbf{1}$ & Western EU \\
\hline 2 & c.1408insG & 1636insG & FS; p.Glu470GlufsX5 & 10 & 1 & Not specified \\
\hline 3 & c.2806_2809del4 & 3034delAAAC & FS; p.Lys936LysfsX23 & 11 & 1 & Western EU, Spanish, Czech \\
\hline 4 & c. $3076 \mathrm{~A}>\mathrm{T}$ & $3304 \mathrm{~A}>\mathrm{T}$ & NS; p.Lys1026X & 11 & 2 & Czech \\
\hline 5 & c.5645C $>A$ & $5873 \mathrm{C}>\mathrm{A}$ & NS; p.Ser1882X & 11 & 2 & Western, Central EU \\
\hline 6 & c.5946delT & $6174 \mathrm{delT}$ & FS; p.Ser1982ArgfsX21 & 11 & 1 & Ashkenazi \\
\hline 7 & c.6589delA & $6817 \mathrm{delA}$ & FS; p.Thr2197LeuX7 & 11 & 1 & Only in Slovakia \\
\hline 8 & c.9098dupA & 9326insA & FS; p.Thr3033AsnfsX9 & 23 & 1 & $\begin{array}{l}\text { Ashkenazi, Hungarian, USA, } \\
\text { Spanich, Western EU }\end{array}$ \\
\hline 9 & c.9403delC & $9631 \mathrm{delC}$ & FS; p.Leu3135PhefsX27 & 25 & 2 & Polish, Czech \\
\hline
\end{tabular}

Table 3. The spectrum of the variants of uncertain clinical significance identified in BRCA1 and BRCA2 genes in Slovak HBOC families. Abbreviations: aa, amino acid; nt, nucleotide; del, deletion; ins, insertion; *, novel mutation; FS, frame-shift; IS, intronic splicing; MS, missense.

\begin{tabular}{|lllllll|}
\hline $\begin{array}{l}\text { No } \\
\text { Approved } \\
\text { nomen. (aa) }\end{array}$ & $\begin{array}{l}\text { Approved nomen. } \\
\text { (nt) }\end{array}$ & $\begin{array}{l}\text { Mutation } \\
\text { type }\end{array}$ & Exon & Families & $\begin{array}{l}\text { Association with } \\
\text { pathogenic mutation }\end{array}$ \\
\hline & & BRCAI
\end{tabular}




\begin{tabular}{|c|c|c|c|c|c|c|}
\hline 1 & p.GIn356Arg & c. $1067 \mathrm{~A}>\mathrm{G}$ & MS & 11 & 68 & 16 \\
\hline 2 & p.Arg496His & c. $1486 \mathrm{C}>\mathrm{T}$ & MS & 11 & 1 & 0 \\
\hline 3 & p.Arg496Cys & c. $1487 \mathrm{G}>\mathrm{A}$ & MS & 11 & 1 & 0 \\
\hline 4 & p.Pro568Arg & c. $1703 \mathrm{C}>\mathrm{G}$ & MS & 11 & 1 & 0 \\
\hline 5 & p.Asn630Asp & c. $1888 \mathrm{~A}>\mathrm{G}$ & MS & 11 & 1 & 0 \\
\hline 6 & p.GIn804His & c. $2412 \mathrm{G}>\mathrm{C}$ & MS & 11 & 1 & 1 \\
\hline 7 & p.Arg841Trp & c. $2521 \mathrm{C}>\mathrm{T}$ & MS & 11 & 1 & 0 \\
\hline 8 & p.Asn916Thr & c. $2748 \mathrm{~T}>\mathrm{C}$ & MS & 11 & 1 & 0 \\
\hline 9 & p.Ser1040Asn & c. $3119 \mathrm{G}>\mathrm{A}$ & MS & 11 & 11 & 2 \\
\hline 10 & p.Lys1109Asn & c. $3327 \mathrm{~A}>\mathrm{T}$ & MS & 11 & 1 & 0 \\
\hline 11 & p.Val1181Ile & c. $3524 \mathrm{G}>\mathrm{A}$ & MS & 11 & 1 & 0 \\
\hline 12 & p.Thr1246Asn & c. $3737 \mathrm{C}>\mathrm{A}$ & MS & 11 & 2 & 2 \\
\hline 13 & p.Glu1345Lys & c. $4036 \mathrm{G}>\mathrm{A}$ & MS & 11 & 1 & 0 \\
\hline 14 & p.Glu1346Gly & c. $4039 \mathrm{~A}>\mathrm{G}$ & MS & 11 & 1 & 0 \\
\hline 15 & p.Ser1512Ile & c. $4535 \mathrm{G}>\mathrm{T}$ & MS & 15 & 1 & 0 \\
\hline 16 & p.Met1652Ile & c. $4956 \mathrm{G}>\mathrm{A}$ & MS & 16 & 14 & 0 \\
\hline 17 & -- & c.5075-53C $>\mathrm{T}$ & IS & $17 / 18$ & 4 & 0 \\
\hline 18 & p.Gly1738del & c.5213delGGA & FS & 20 & 2 & 0 \\
\hline 19 & -- & c.5277+60ins12 & IS & $20 / 21$ & 4 & 0 \\
\hline \multicolumn{5}{|c|}{ Number of families totally } & 117 & 19 \\
\hline \multicolumn{7}{|c|}{$B R C A 2$} \\
\hline 1 & -- & c.1909+12delT & IS & $10 / 11$ & 7 & 1 \\
\hline 2 & p.Lys1025Asn & c. $3075 \mathrm{G}>\mathrm{T}$ & MS & 11 & 1 & 1 \\
\hline 3 & p.Val1643Ala & c. $4928 \mathrm{~T}>\mathrm{G}$ & MS & 11 & 1 & 0 \\
\hline 4 & p.Thr1915Met & c. $5744 \mathrm{C}>\mathrm{T}$ & MS & 11 & 4 & 0 \\
\hline 5 & p.Ser2052Leu & c. $6155 \mathrm{C}>\mathrm{T}$ & MS & 11 & 1 & 0 \\
\hline 6 & p.Gly2274Val & c. $6821 \mathrm{G}>\mathrm{T}$ & MS & 11 & 1 & 0 \\
\hline 7 & p.Trp2626Cys & c. $7878 \mathrm{G}>\mathrm{C}$ & MS & 17 & 1 & 0 \\
\hline 8 & p.Val2908Gly & c. $8723 \mathrm{~T}>\mathrm{G}$ & MS & 21 & 1 & 0 \\
\hline \multicolumn{5}{|c|}{ Number of families totally } & 17 & 2 \\
\hline
\end{tabular}

Table 4. Detected missense uncertain variants in BRCA1/2 genes. Characterization of substituted aminoacids and protein prediction. Abbreviations: aa, amino acid; mol. size, molecular size; sec. struc., secondary structure; BIC, Breast Cancer information core; neu, neutral; path, pathogenic.

\begin{tabular}{|c|c|c|c|c|c|c|c|c|}
\hline \multirow{2}{*}{ UVs } & \multicolumn{2}{|c|}{ Wild-type aa } & \multicolumn{2}{|c|}{ Mutant aa } & \multirow{2}{*}{ PolyPhen } & \multirow{2}{*}{ AGVGD } & \multirow{2}{*}{ PMut } & \multirow{2}{*}{$\begin{array}{c}\text { Times } \\
\text { reported } \\
\text { (BIC) }\end{array}$} \\
\hline & Charge & Mol. size & Charge & Mol. size & & & & \\
\hline & & $\overline{B R C A I}$ & & & & & & \\
\hline p.GIn356Arg & acide, hydrophile & 146.15 & positive, basic & 174.2 & probable 2.08 & $\mathrm{C} 35$ & 0.20 neu (5) & $92 x$ \\
\hline p.Arg496His & positive, alkaline & 174.2 & basic, aromatic & 155.16 & benign 0.75 & $\mathrm{C} 25$ & 0.46 neu $(0)$ & $90 x$ \\
\hline
\end{tabular}




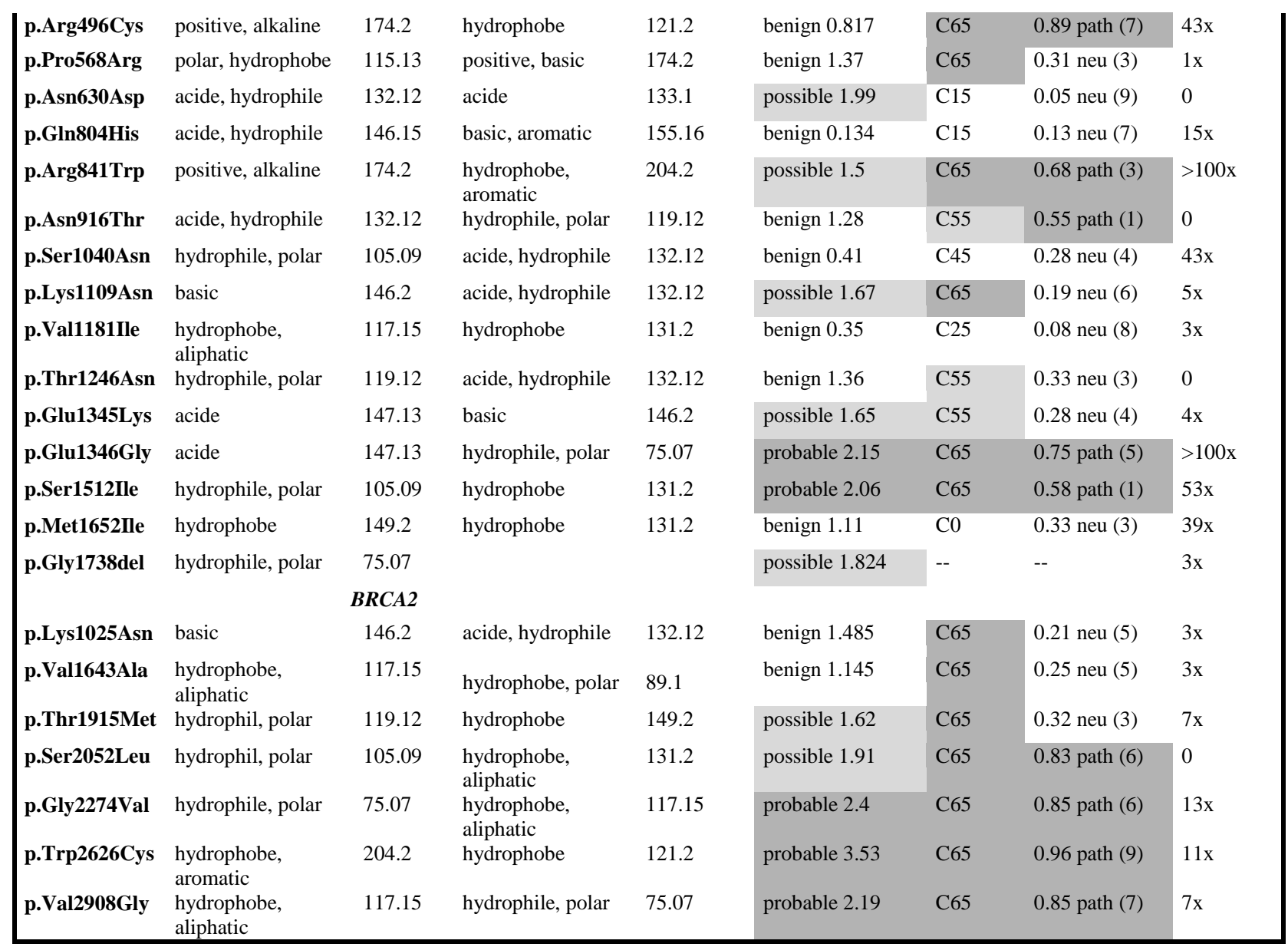

Table 5. The spectrum of probable haplotypes represented by mutations identified in BRCA1 gene in Slovak HBOC families.

\begin{tabular}{|lll|}
\hline \multicolumn{2}{|l|}{ Probable $\boldsymbol{B R C A 1}$ haplotypes } & $\begin{array}{l}\text { Number of } \\
\text { families }\end{array}$ \\
\hline 1 & p.Ser694Ser, p.Leu771Leu, p.Pro871Leu, p.Glu1038Gly, p.Lys1183Arg, p.Ser1436Ser, p.Ser1613Gly, c.4987- & 182 \\
& 68G>A, c.5152+66G/A & 172 \\
2 & Wild-type (without any detected mutation) & 61 \\
3 & p.Gln356Arg & 61 \\
\hline
\end{tabular}




\begin{tabular}{|llc|}
\hline 4 & c.5266dupC & 32 \\
5 & p.Asp693Asn, p.Ser694Ser, p.Leu771Leu, p.Pro871Leu, p.Glu1038Gly, p.Lys1183Arg, p.Ser1436Ser, & 28 \\
& p.Ser1613Gly, c.4987-68G>A, c.5152+66G/A & 13 \\
6 & p.Ser1040Asn & 14 \\
7 & p.Cys61Arg, p.Gln356Arg & 10 \\
8 & p.Ser694Ser, p.Leu771Leu, p.Pro871Leu, p.Glu1038Gly, p.Lys1183Arg, p.Ser1436Ser, p.Ser1613Gly, & 5 \\
& p.Met1652Ile, c.4987-68G>A, c.5152+66G/A & 5 \\
9 & p.Asp693Asn, p.Ser694Ser, p.Leu771Leu, p.Pro871Leu, p.Glu1038Gly, p.Lys1183Arg, p.Ser1436Ser, & 3 \\
& p.Ser1613Gly, c.4987-68G>A, c.5152+53C/T, c.5152+66G/A & 3 \\
10 & p.Pro871Leu & 2 \\
11 & p.Ser1652Ile & 2 \\
12 & c.68_69del2 & 2 \\
13 & p.Thr1246Asn, c.4065_4068del4 & 2 \\
14 & c.4986+4A/T & 2 \\
\hline
\end{tabular}

49. 


\section{Copyright Transfer Statement \\ BREAST CANCER RESEARCH AND TREATMENT}

The copyright to tris article is transterred to Springer (respective to owner if other than Springer and for U.S. govermment amployees; to the extont transterabie) efluctive it and when the article is accopted for publication. The copynight transter covers the exclusive right to reproduce and distributo the article, inciuding reprints, translations, photographle reproductions, mioroferm, electronic form (offine, online) or any other roproduotions of ainilar nature.

An author may set-archive an authonereated version of his/her article on his/her own websile and hisher institution's ropository, including hisher final wersions however hel she may not use fhe publashers PDF varsion which is posted on www.springerlik.com. Furthermote, the auther may anly post hisher version provided ecknowlechement is given to the original source of pubitication and a fink is inserted to the publahed article on Springer's wobste. The ink must be accompanied by the following text: "The original publication is available at www.sprinperlink.com"

Plesse use the appropriate DOI for the article (go to the Linking Options in the articto, fenen to OpenUFL and use the link with the DOH. Articies disseminetad via wrows in the articio, then to indexod, abstrected, and referenced by many abetracting and information sterveces. bebliopraphie networks, subscription agencles, library natworks, and consortia.

The author warrants that this contribution is orginal and that hoishe has full power to make this grant. The austor signs for and accepts responelodty for rubating this material on behaif of any and aff co-atathors.

Financiat Disciosure/Confilet of Interest Statement

1, the undersigned author, certify that the authors of the Article have no commexcial association (e.0. consultancien, stock ownership, eovily interests, patant-liconsing arrangements, ets.) that might pose a contict of interest in connection with the submithed artick, excopt as fiesciosed on a separate attachmont. Alt funding sources supperting the work and all instititional or corporate atlitiations of the authors are ackonowledged in a footnote.

D. Check here it a seperate athachment is enclosed

Atter submission of this agreament signed by tho corrosponding author changos of authorahip of in the orier of the authors listed will not be accaoted by Springer.

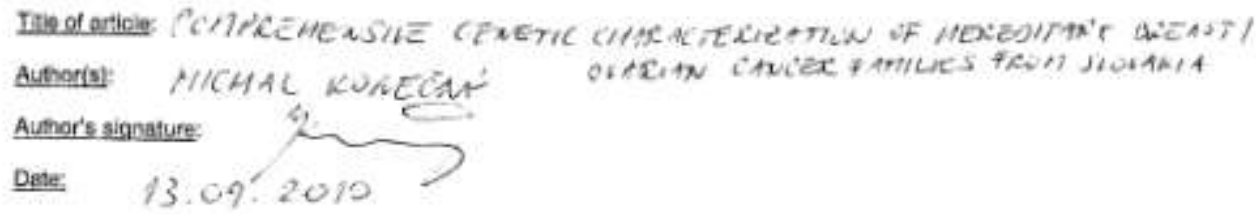

